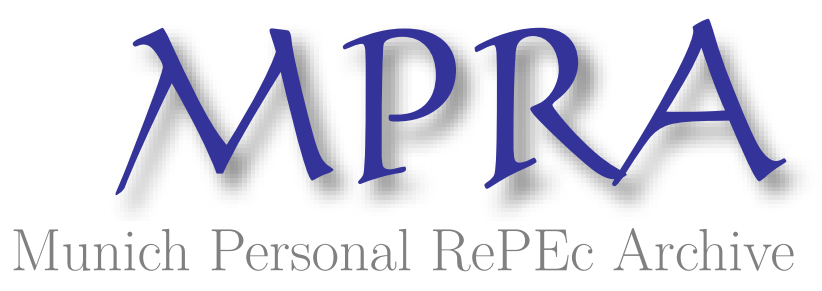

\title{
A New Assessment of the Chinese RMB Exchange Rate
}

Zhang, Zhibai and Chen, Langnan

26 August 2013

Online at https://mpra.ub.uni-muenchen.de/49315/

MPRA Paper No. 49315, posted 26 Aug 2013 17:21 UTC 


\title{
A New Assessment of the Chinese RMB Exchange Rate
}

\author{
Zhibai Zhang* \\ Economics \& Management College, Zhaoqing University, China \\ and \\ Langnan Chen \\ Lingnan (University) College and Institute for Economics, Sun Yat-sen University, China
}

\begin{abstract}
Summary. - The ratio, Penn effect and behavioral equilibrium exchange rate (BEER) are used to assess the level of the bilateral real exchange rate (RER) of the Chinese RMB against the US dollar in 1980-2012. The statistical indexes and economic meaning indicate that the findings from the BEER and ratio model are more reasonable. Based on the two models, the RMB was overvalued by $10-20 \%$ in 2011-2012. Given the already overvalued currency and the not-ideal economic situation of China, such a fast RER appreciation of $6.6-6.7 \%$ per year as it was in 2005-2012 is not sustainable. Further, corresponding policy proposals are given.

Key words - Chinese RMB, Misalignment, Ratio model, Penn effect, Behavioral equilibrium exchange rate
\end{abstract}

\section{INTRODUCTION}

The internal and external economic environments that China faces in the last few years have changed greatly. As China has become deeply involved in the global economic cycles, it is hard hit by the current global economic slowdown which was perhaps firstly sparked by the U.S. subprime crisis in 2007 and then again by the European debt crisis in 2010. According to the IMF's International Financial Statistics (IFS) database, China's annual real GDP growth ratio was $10.3 \%$ in 2010, 9.4\% in 2011, and 7.8\% in 2012. The latest data on the first half of 2013 (real GDP growth ratio was $7.6 \%$, year by year) indicates that China's slowdown may continue. ${ }^{\dagger}$ In contrast with the not-ideal economic situation, the RMB appears to be appreciating steadily. Based on the IFS, the RMB real effective exchange rate index (CPI-based, 2005 = 100) rose from 115.4 in January 2010 to 137.1 in May 2013, and the nominal exchange rate (yuans per US dollar) rose from 6.83 in January 2010 to 6.17 in June 2013. Given the above seemingly perplexing phenomenon, we wonder how the RMB misalignment appears in recent years and whether the current trend of RMB is proper. That is, we want to give it a new assessment.

There are many models used in currency valuation (Égert et al., 2006; Isard, 2007; Bussière et al., 2010). For the RMB valuation, Yang and Bajeux-Besnainou (2006) used the purchasing power parity (PPP) model, Frankel (2006) and Cheung et al. (2007) used the Balassa-Samuelson (BS) regression or the Penn effect model, Funke and Rahn (2005) and Bénassy-Quéré and lahrèche-Révil (2008) used the behavioral equilibrium exchange rate (BEER) model, Lopez-Villavicencio et al. (2012) and Sato et al. (2012) used the macroeconomic balance or fundamental equilibrium

\footnotetext{
* Zhibai Zhang (corresponding author)

Economics \& Management College, Zhaoqing University, Zhaoqing City 526061, Guangdong Province, China E-mail addresses: zzhang5678@163.com, zhibai.zhang@gmail.com

${ }^{\dagger}$ News release (in Chinese), http://cn.reuters.com/article/cnBizNews/idCNL4SOFL0H420130715?sp=true
} 
exchange rate model, and Zhang (2012a) used the ratio model. In his conclusion to a detailed review, Isard (2007, p. 35) suggested that the assessment of equilibrium exchange rates should be informed through the application of several different methodologies. Therefore, we use three models (ratio, Penn effect and BEER) in this paper. The three models are chosen because (1) they have relationships in theory base and model specification (see Section 2.1) and (2) the ratio model needs modification when used in China, which is not noted by Zhang (2012a).

The rest of the paper proceeds in the following manner. Section 2 presents the models and data. Section 3 is the econometric analysis. Section 4 analyzes the reasonability of the model findings derived in Section 3. Section 5 discusses what caused the RMB overvaluation in 2011-2012. Section 6 gives our policy proposal. Finally, Section 7 concludes the paper.

\section{MODELS AND DATA}

Before introducing the models, the definition of real exchange rate (RER) must be given. In this paper, RER is defined by Eq. (1), where $P_{i}$ is the domestic price level of a country, $P^{*}$ is the price level of a foreign country (in this paper, the United States), and $N E R_{i}$ (nominal exchange rate) is expressed as the national currency units per US dollar. Based on this definition, a greater value of RER represents the local currency's appreciation (against the US dollar). The RER in this definition also measures the relative price level between two countries in terms of a common currency. Thus, it is also called "the price level of the GDP of one country relative to that of the US" in the Penn World Tables database.

$R E R_{i}=\frac{P P P_{i}}{N E R_{i}}=\frac{P_{i} / P^{*}}{N E R_{i}}=\frac{P_{i}}{N E R_{i} \times P^{*}}$

\section{(a) Models}

Both ratio and Penn effect models are based on an empirical regularity, which is depicted in Fig. 1.

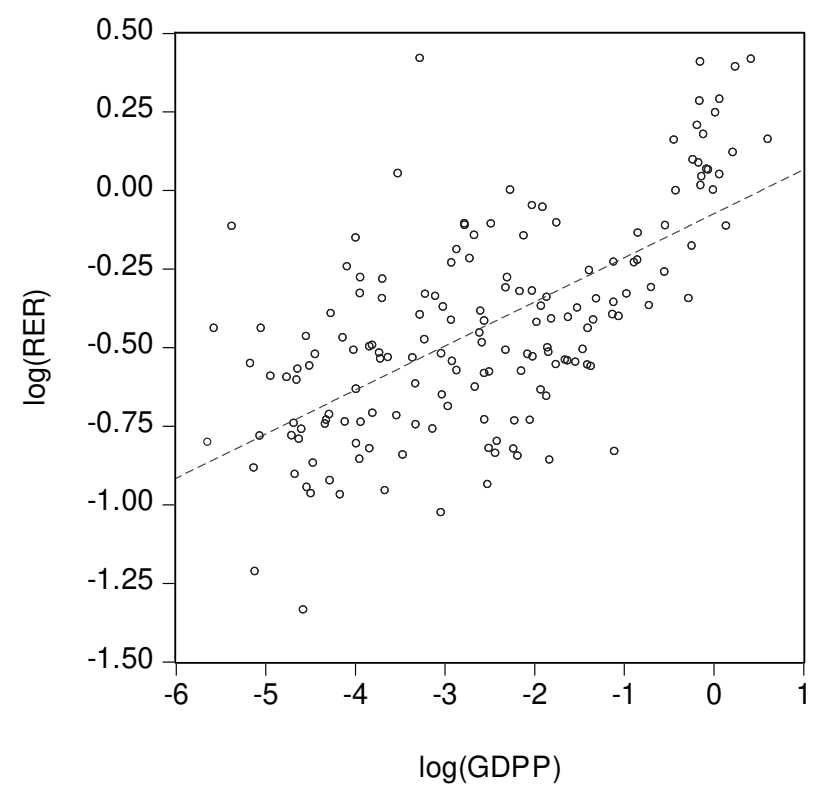

Figure1. RERs and GDPPs (GDP per capita), in logarithm, of 165 countries and areas in 2012. 
Source: World Bank's World Development Indicators (WDI) online database.

${ }^{\text {a }}$ RER (defined by Eq. (1)) and GDP per capita (constant 2005 US\$) are both normalized, with the US = 1 .

Fig. 1 tells us that, from a global view, a RER in a higher income-level country is often greater than that in a lower income-level country; or the price level in a higher income-level country is often greater than that in a lower income-level country, measured by one common currency (Balassa, 1964; Kravis and Lipsey, 1982; Samuelson, 1994; Rogoff, 1996; Frankel, 2006; Isard, 2007). This regularity is called the BS effect (Chang and Shao, 2004; Frankel, 2006), "Penn effect" (Samuelson, 1994; Isard, 2007; Cheung et al., 2010), "(long-run) deviations from PPP” (Rogoff, 1996), or others. Given that the Penn effect essentially refers to this empirical regularity (Samuelson, 1994) and that the BS effect is only one of its explanations (Rogoff, 1996), with the BS effect being an invalid explanation in some cases (Ito et al, 1997; Isard, 2007), the Penn effect is the more suitable name. Therefore, we call this regularity the Penn effect following Isard (2007) and Cheung et al. (2010).

Because of the existence of the Penn effect, the PPP theory does not hold between a poor and a rich country. This limitation, however, gives an idea of where the ratio and Penn effect models were born.

The ratio model, which is proposed by Zhang (2012a), uses a simple ratio relationship (Eq. (2)) to value a RER. In Eq. (2), $R E R_{i}$ is defined by Eq. (1). GDPP ${ }_{i}$ is country $i$ 's per capita GDP relative to that of the US (where the US =1). Based on the ratio model, a RER should be equal to the country's GDPP (both relative to the US where the US $=1$, hereafter) that is just the equilibrium RER. That is, if the value of Ratio is one, the RER is said in equilibrium. If the value of Ratio is $_{i}$ more than one (or less than one), the RER is concluded as overvalued (or undervalued). For example, according to the WDI, in 2012, the RER and GDPP of Japan were 1.33 and 0.935 , respectively. Thus, the Ratio is greater than one $(1.33 / 0.935=1.42)$, and the yen was overvalued by $29.7 \%$ (the yen should depreciate $29.7 \%,=(1.33-0.935) / 1.33$, to its equilibrium value $)$.

Ratio $_{i}=\frac{R E R_{i}}{G D P P_{i}}$

The Penn effect model was originally used in a cross-section data setting (Chang and Shao, 2004; Frankel, 2006) and then used in a panel data setting (Cheung et al., 2007; Garroway et al., 2012). Its panel data specification in this paper is Eq. (3), where $R E R_{i t}$ is defined by Eq. (1), GDPP ${ }_{i t}$ (GDP per capita) is relative to the US (where the US = 1), and log means taking the logarithm. As Eq. (3) regresses the RERs on the GDPPs, the deviations from the regression line represent the over- or undervaluation of the RERs when the Penn effect is considered (Chang and Shao, 2004) .

$\log \left(R E R_{i t}\right)=\beta_{0}+\beta_{1} \log \left(G D P P_{i t}\right)+\delta_{i}+\gamma_{t}+\epsilon_{i t}$

The BEER model was originally used in a time-series setting (Clark and MacDonald, 1998; MacDonald, 1999; Funke and Rahn, 2005) and then used in a panel data setting (Maeso- Fernandez, et al., 2006; Dubas, 2009; Elbadawi, et al., 2012). This model is perhaps the most popular one used in currency valuation. Its panel data specification in this paper is Eq. (4), where $R E R_{i t}$ is defined by Eq. (1), GDPP $P_{i t}$ is per capita GDP relative to the United States (the US $=1$ ) as before, and NFA is net foreign assets, also a popular explanatory variable used in the BEER model (see Funke and Rahn (2005) and Alper and Civcir (2012)). As some values for NFA are negative, the logarithm form cannot be used on NFA (though, can be used on the other two variables).

$\log \left(R E R_{i t}\right)=\beta_{0}+\beta_{1} \log \left(G D P P_{i t}\right)+\beta_{2} N F A_{i t}+\delta_{i}+\gamma_{t}+\epsilon_{i t}$ 
The main relations between the three models are as follows. Both ratio and Penn effect models are based on the same empirical regularity, the Penn effect. But the ratio model uses a simple ratio relationship, while the Penn effect model uses a regression analysis. The ratio model can be viewed as a special form of the Penn effect model when the following two conditions both hold: (1) the coefficients $\beta_{0}$ and $\beta_{1}$ in Eq. (3) are zero and one simultaneously; (2) the variables in Eq. (3) don't take logarithms. Zhang (2012b, p. 146) discussed the relationship of the Penn effect and BEER models in panel data setting. Concretely, the number and definition of the variables in the Penn effect model must be strictly the same as those in Eq. (3), but the number and definition of the variables in the BEER model can be quite diverse. The Penn effect model can be viewed as a special form of the BEER model, when the explained and explanatory variables of the BEER model are specially constrained. The BEER model includes the Penn effect model but also includes other specified models that do not belong to the Penn effect model. In this paper, concretely, if the variable NFA in Eq. (4) is not used, the BEER model will reduced to be the Penn effect model.

(b) Data

All data are from the World Bank's World Development Indicators (WDI) online database. RER is defined by Eq. (1). GDPP (GDP per capita, in current US dollars) is relative to that of the US (with the US $=1$ ) as defined in Eqs. (2)-(4). ${ }^{3}$ The NFA is originally measured by current local currency and we convert it into measurement by the common US dollar using NER. The RER and GDPP are used in the ratio and Penn effect models, while NFA, along with the other two variables, is used in the BEER model.

We first sequence all the global countries by their GDP (in current US dollars) and choose the largest 29 ones among them; the GDP of each country represents greater than $0.5 \%$ of that of the world. Euro countries adopted inconsistent currencies before and after 1999, so we delete Germany, France, Italy, Spain, Netherlands, Belgium, and Austria. In the 22 biggest countries left, Russia, Poland, and Argentina are again deleted because of their many blank values for the variables. In the end, 19 of the biggest countries are left and used: United States, China, Japan, United Kingdom, Brazil, India, Canada, Australia, Mexico, Korea (Rep.), Indonesia, Turkey, Switzerland, Sweden, Norway, South Africa, Venezuela, Colombia, and Thailand; their collective GDP represented 67.6\% of the world GDP in 2012.

The values for RER for all the countries and areas before 1980 are not obtained, so the sample period chosen is $1980-2012$.

\section{ECONOMETRIC ANALYSIS}

\section{(a) On the ratio model}

When using the ratio model in the RMB valuation, the model needs a modification. Why?

China significantly differs from the US in many respects. Most obviously, based on the WDI and in 2012, China has a population of 1.35 billion, and its GDP per capita is only $12.2 \%$ of that of the

\footnotetext{
${ }^{3}$ We use GDPP measured by the current US dollar and not by constant 2005 US dollars because: (1) the NER (in RER) and NFA are both measured by the current US dollar and GDPP also measured by the current US dollar should give a more comparable result; (2) the coefficients on $\log$ (GDPP) in Eq. (3) and Eq. (4) obtained by using the current US dollar are both positive and significant, which is consistent with the Penn effect, while those obtained by using constant US dollars are both negative and significant, which is in conflict with the Penn effect.
} 
US, which has a population of 0.314 billion and almost equal land area. Besides, China is a socialist state whose economy is largely dominated by state-owned enterprises and whose regional economic development is very imbalanced; while the US is a free market economy that is largely dominated by private enterprises and its regional economic development is less imbalanced. These differences means that directly using the ratio model on the RMB is not proper and we should give it some modifications. Since taking all these differences into the model is not realistic, we only take the difference in the population. Concretely, the equilibrium RER is modified as the GDPP multiplying the ratio of China's population to the US's population. For example in 2012, RMB RER was 0.66, the GDPP in Eq. (2) (the ratio of China's GDPP to the US's GDPP) originally was 0.122 , the ratio of China's population to the US's population was 4.3, and therefore the GDPP used in Eq. (2) (i.e., the equilibrium RMB RER) is modified to be $0.525(=0.122 \times 4.3)$ instead of 0.122 . In every year, the GDPP used in Eq. (2) is modified in the same way.

Using the modified GDPP, the misalignment obtained from the ratio model, as well as those from the Penn effect and BEER models, are given in Table 1.

In Table 1, the misalignments are calculated by using (RER-equilibrium RER)/RER, as used in Bénassy-Quéré and lahrèche-Révil (2008). In this definition, the misalignment is just the needed appreciation or depreciation of the RER. For example in 2012, the RMB RER was 0.66 and its equilibrium value was 0.525 , so the RMB RER should depreciate by $20.5 \%$ [ $=(0.66-0.525) / 0.66$ ] to its equilibrium value. In this case, the RMB RER was overvalued by $20.5 \%{ }^{4}$

Table 1. RMB RER misalignments obtained from the three models

\begin{tabular}{cccccccc}
\hline year & Ratio & Penn effect & BEER & year & Ratio & Penn effect & BEER \\
\hline 1980 & $91.1 \%$ & $43.3 \%$ & $39.4 \%$ & 1997 & $72.6 \%$ & $-8.5 \%$ & $-18.3 \%$ \\
1981 & $90.9 \%$ & $40.6 \%$ & $36.8 \%$ & 1998 & $71.7 \%$ & $-6.0 \%$ & $-16.5 \%$ \\
1982 & $89.9 \%$ & $38.4 \%$ & $34.3 \%$ & 1999 & $71.0 \%$ & $-10.0 \%$ & $-20.7 \%$ \\
1983 & $89.3 \%$ & $38.3 \%$ & $33.5 \%$ & 2000 & $69.8 \%$ & $-10.4 \%$ & $-21.0 \%$ \\
1984 & $88.5 \%$ & $36.6 \%$ & $31.2 \%$ & 2001 & $67.7 \%$ & $-8.4 \%$ & $-18.6 \%$ \\
1985 & $87.4 \%$ & $37.0 \%$ & $30.8 \%$ & 2002 & $65.4 \%$ & $-12.1 \%$ & $-21.8 \%$ \\
1986 & $86.8 \%$ & $29.4 \%$ & $22.8 \%$ & 2003 & $62.8 \%$ & $-20.9 \%$ & $-29.7 \%$ \\
1987 & $85.7 \%$ & $15.6 \%$ & $9.8 \%$ & 2004 & $60.5 \%$ & $-25.5 \%$ & $-30.1 \%$ \\
1988 & $84.7 \%$ & $10.4 \%$ & $4.5 \%$ & 2005 & $57.3 \%$ & $-31.4 \%$ & $-31.4 \%$ \\
1989 & $84.6 \%$ & $11.6 \%$ & $4.7 \%$ & 2006 & $53.1 \%$ & $-34.0 \%$ & $-27.6 \%$ \\
1990 & $84.3 \%$ & $8.2 \%$ & $2.9 \%$ & 2007 & $47.5 \%$ & $-37.0 \%$ & $-21.9 \%$ \\
1991 & $82.8 \%$ & $3.4 \%$ & $-2.1 \%$ & 2008 & $42.2 \%$ & $-32.3 \%$ & $-5.3 \%$ \\
1992 & $81.0 \%$ & $-3.9 \%$ & $-10.4 \%$ & 2009 & $34.9 \%$ & $-33.6 \%$ & $-1.9 \%$ \\
1993 & $79.0 \%$ & $-13.1 \%$ & $-20.9 \%$ & 2010 & $29.8 \%$ & $-40.4 \%$ & $-0.1 \%$ \\
1994 & $77.2 \%$ & $-12.1 \%$ & $-20.9 \%$ & 2011 & $24.6 \%$ & $-38.6 \%$ & $8.8 \%$ \\
1995 & $75.3 \%$ & $-10.3 \%$ & $-20.1 \%$ & 2012 & $20.5 \%$ & $-38.1 \%$ & $11.4 \%$ \\
1996 & $73.8 \%$ & $-8.6 \%$ & $-18.7 \%$ & & & & \\
\hline
\end{tabular}

${ }^{\text {a }}$ Positive (negative) values represent overvaluation (undervaluation). The misalignments for the Penn effect and BEER models are obtained from the regressions in 1980-2012.

\footnotetext{
${ }^{4}$ The other misalignment is measured by (RER - equilibrium RER) / equilibrium RER, as in Zhang (2012a). Note that the two types of misalignments are different. For this example, if we use the definition of Zhang (2012a), the RMB was undervalued by $25.7 \%$ [ $=(0.66-0.525) / 0.525]$ (not $20.5 \%)$ in 2012. But the two expressions can be transformed. Let $x=($ RER - equilibrium RER $) /$ equilibrium RER, $y=(R E R-$ equilibrium RER $) / R E R$, then $y=x$ $/(1+\mathrm{x})$.
} 
Table 1 shows that, based on the ratio model, the RMB RER was overvalued in 1980-2012, with a declining trend from about $90 \%$ in 1980 to about $20 \%$ in 2012. This result is similar to that in Zhang (2012a) in terms of the trend of the misalignment change. Since the GDPP here is modified, the degree of the misalignment has been greatly reduced compared with that in Zhang (2012a).

\section{(b) On the Penn effect model}

Table 2 gives the results of redundant fixed effect tests. The associated p-values of the statistics strongly reject the null hypothesis that the cross-section effects, period effects, or both of the effects are redundant. Thus, the two-way fixed effects estimation is appropriate and is then used.

Table 2. Redundant fixed effects tests for the Penn effect model in 1980-2012

\begin{tabular}{lccc}
\hline Effects test & Statistic & Degree of freedom & P-value \\
\hline Cross-section F & 26.38 & $(18,575)$ & 0.0000 \\
Cross-section Chi-square & 377.45 & 18 & 0.0000 \\
Period F & 2.43 & $(32,575)$ & 0.0000 \\
Period Chi-square & 79.38 & 32 & 0.0000 \\
Cross-Section/Period F & 12.36 & $(50,575)$ & 0.0000 \\
Cross-Section/Period Chi-square & 457.65 & 50 & 0.0000 \\
\hline
\end{tabular}

a Total panel (balanced) observations: 627 .

The main estimation result is given in Eq. (5). Values in parentheses below the coefficients are their t-statistics (second line) and associated p-values (third line) respectively, where White cross-section standard errors and covariance are used. The slope coefficient is highly significant, confirming the existence of the Penn effect. $\mathrm{R}^{2}=0.914$ means that the regression is a good fit.

$\log \left(R E R_{i t}\right)=0.267+0.413 \times \log \left(G D P P_{i t}\right)+\delta_{i}+\gamma_{t}+\epsilon_{i t}$

$$
\begin{aligned}
& \left(\begin{array}{ll}
(.73) & (10.72) \\
(0.00) \quad(0.00)
\end{array}\right. \\
& \mathrm{R}^{2}=0.914 \quad \text { observations }=627
\end{aligned}
$$

The equilibrium RER from the Penn effect model, the fitted value of RER, can be solved from Eq. (5). Then the misalignment can be obtained and is (already) given in the above Table 1.

\section{(c) On the BEER model}

Tabel 3 gives the redundant fixed effect tests for the BEER model. Similar to the case of the Penn effect model, the associated p-values of the statistics strongly reject the null hypothesis that the cross-section effects, period effects, or both of the effects are redundant. Therefore, in the BEER model, the two-way fixed effects estimation is also appropriately used.

Table 3. Redundant fixed effects tests for the BEER model in 1980-2012

\begin{tabular}{lccc}
\hline Effects test & Statistic & Degree of freedom & P-value \\
\hline Cross-section F & 31.89 & $(18,561)$ & 0.0000 \\
Cross-section Chi-square & 432.67 & 18 & 0.0000 \\
Period F & 2.15 & $(32,561)$ & 0.0003 \\
Period Chi-square & 71.06 & 32 & 0.0001 \\
Cross-Section/Period F & 14.36 & $(50,561)$ & 0.0000 \\
Cross-Section/Period Chi-square & 506.10 & 50 & 0.0000 \\
\hline
\end{tabular}

a The panel is unbalanced (total observations: 614) because the data for NFA in some years in four countries are blank. 
The main estimation result is given in Eq. (6). Values in parentheses below the coefficients are their t-statistics (second line) and associated p-values (third line) respectively, where White cross-section standard errors and covariance are used. The coefficient on $\log (\mathrm{GDPP})$ is highly significant and correctly signed. The sign of NFA is not predicted but expected because the negative relationship between NFA and RER is consistent with many previous findings (Alper and Civcir, 2012, p. 122). Adjusted $R^{2}=0.913$ means that the regression is a good fit. The equilibrium RER from the BEER model, the fitted value of RER, can be solved from Eq. (6). Then the misalignment can be obtained and is (already) given in the above Table 1.

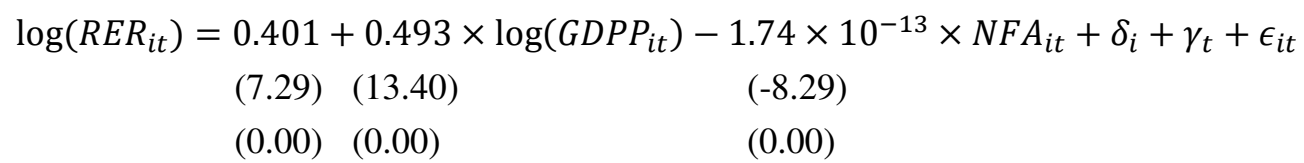

Adjusted $\mathrm{R}^{2}=0.913 \quad$ observations $=614$

We also consider the non-stationary panel data method in the cases of the Penn effect and BEER models. The LLC unit root test indicates all the variables are I(1), and the Johansen Fisher panel cointegration test indicates there is a cointegration relationship in each group. The panel data dynamitic OLS is then used to obtain the cointegration coefficients. The misalignments derived from the non-stationary panel data are similar to those listed above. For example, the absolute value of the difference between the misalignment from the OLS estimation BEER and that form the dynamitic OLS estimation BEER is mostly less than 0.05 in the common period. So they are omitted. ${ }^{5}$

\section{WHICH MODEL FINDING IS MORE REASONABLE?}

It can be seen easily that the misalignment results obtained from different models (Table 1) are different. For example, the RMB was overvalued by $91.1 \%, 43.3 \%$ and $39.4 \%$ in 1980 from the ratio, Penn effect and BEER models respectively; while it was overvalued by $20.5 \%$ and $11.4 \%$ from the ratio and BEER models respectively but was undervalued by $38.1 \%$ from the Penn effect model in 2012. Given the above different misalignments from the three models, we wonder which model finding is more reasonable.

\section{(a) Based on statistic index reasonability}

One way to judge whether a model finding is more reasonable than the other is to see how close the calculated equilibrium RER is to its actual value (RER). This can be done by using the following two statistics: root mean squared error (RMSE) and mean absolute error (MAE). The two statistics are introduced in Wooldridge (2006, p. 661) and are also used by Meese and Rogoff (1983, p. 11), whose definitions are given below. It should also be noted incidentally that there are some differences between the paper by Meese and Rogoff (1983) and this paper. Meese and Rogoff (1983) focused on the financial market, studied NERs, and compared structural models with the random walk and vector autoregression models (which have lagged explained variables as the explanatory ones). In contrast, in this paper, we focus on the macro-economy, study RERs, and only compare

\footnotetext{
${ }^{5}$ In addition, Isard (2007) and Dunaway et al. (2009) studied the robustness of equilibrium RER estimations. Actually, each conclusion derived from an econometric method, including but not confined to equilibrium RERs, may inevitably depend to some degree on the data, model specification, variable, and period used. The robust exercises, though tried in many different ways, are always limited. Therefore we do not give other possible robustness exercises.
} 
one structural model with other structural models (which do not have lagged explained variables as the explanatory ones). Just because all equations that we use are structural, the forecasting in this paper is, and has to be, static and in-sample.

$$
\begin{aligned}
& \text { RMSE }=\sqrt{\sum_{t=T+1}^{T+h}\left(\widehat{R E R_{t}}-R E R_{t}\right)^{2} / h} \\
& M A E=\sum_{t=T+1}^{T+h}\left|\widehat{R E R}_{t}-R E R_{t}\right| / h
\end{aligned}
$$

where $\widehat{R E R}_{t}$ denotes the RER's equilibrium (forecasted) value in period t.

For forecasting reasonability, we do not solely use the misalignments listed in Table 1, where the misalignments for the Penn effect and BEER models are obtained from one regression in 1980 2012 respectively, but use a method that is somewhat like the rolling regression used by Meese and Rogoff (1983). Concretely, we use the last eight years, 2005-2012, as the forecasting period. We first calculate the misalignment in 2005 using the data from 1980-2005, the misalignment in 2006 using the data from 1980-2006, and in the end the misalignment in 2012 using the data from 19802012. Then, for these misalignments, we calculate RMSE and MAE, which are listed in Table 4.

Table 4. Forecast error statistics for the three models in 2005-2012

\begin{tabular}{cccc}
\hline & Ratio model & Penn effect model & BEER model \\
\hline RMSE & 0.202 & 0.242 & 0.069 \\
MAE & 0.199 & 0.241 & 0.064 \\
\hline
\end{tabular}

From Table 4, we can see that the values of RMSE decrease strictly from the Penn effect model (0.242) to the ratio model (0.202) and then to the BEER model (0.069), and those of MAE also give the same conclusion (from 0.241 in the Penn effect model to 0.199 in the ratio model and then to 0.064 in the BEER model). That is to say, the misalignment from the BEER model is the best, the misalignment from the ratio model is better, and the misalignment from the Penn effect model is the worst.

\section{(b) Based on economic meaning reasonability}

Zhang (2012b) proposed a criterion for comparing misalignment results from different models based on a common sense of economics. ${ }^{6}$ Specifically, he argued that if a RER depreciates and the concluded degree of undervaluation (overvaluation) increases (decreases), or if a RER appreciates and the concluded degree of undervaluation (overvaluation) decreases (increases), the misalignment will be reasonable; otherwise, it will be less reasonable. In other words, in a reasonable misalignment result, the increase in the degree of undervaluation (overvaluation) corresponds to the depreciation (appreciation), and the decrease in the degree of undervaluation (overvaluation) corresponds to the appreciation (depreciation). For example, since the RMB RER depreciated greatly from about 0.7 in $1980-1981$ to about 0.35 in 1992-1994, a misalignment that "the RMB was overvalued in 1980 and undervalued in 1992" is more reasonable than another misalignment

\footnotetext{
${ }^{6}$ Except for the criteria used by Meese and Rogoff (1983) and Zhang (2012b), Cheung and Chinn (1998) argued that the same statistical properties (integration and cointegration) can be used to judge the forecast reasonability. But heir criterion is not appropriately used here.
} 
that "the RMB was undervalued in 1980 and overvalued in 1992." Here we use the misalignment classification comparison. ${ }^{7}$

We first sequence all the misalignments in each model (Table 1) from overvaluation to undervaluation. Then, we classify the misalignments from the ratio model into three types: greater than $70 \%$, between $50 \%-70 \%$, and less than $50 \%$, and classify the misalignments from the Penn effect and BEER models into the same three types: greater than $10 \%$, between $-10 \%$ and $10 \%$, and less than $-10 \%$. In the end, the corresponding averages of misalignments and of RER are calculated, given in Table 5.

Table 5. Misalignment classification comparison for the three models

\begin{tabular}{|c|c|c|c|c|c|}
\hline \multicolumn{2}{|c|}{ Ratio model } & \multicolumn{2}{|c|}{ Penn effect model } & \multicolumn{2}{|c|}{ BEER model } \\
\hline $\begin{array}{c}\text { Misalignment } \\
\text { (Mis) }\end{array}$ & $\begin{array}{c}\text { Average } \\
\text { RER } \\
(\mathrm{US}=1)\end{array}$ & $\begin{array}{c}\text { Misalignment } \\
\text { (Mis) }\end{array}$ & $\begin{array}{c}\text { Average } \\
\text { RER } \\
(\mathrm{US}=1)\end{array}$ & $\begin{array}{c}\text { Misalignment } \\
\text { (Mis) }\end{array}$ & $\begin{array}{c}\text { Average } \\
\text { RER } \\
(\mathrm{US}=1)\end{array}$ \\
\hline Mis $\geq 70 \%$ & 0.819 & Mis $\geq 10 \%$ & 0.532 & Mis $\geq 10 \%$ & 0.605 \\
\hline $50 \%<$ Mis $<70 \%$ & 0.624 & $-10 \%<$ Mis $<10 \%$ & 0.400 & $-10 \%<$ Mis $<10 \%$ & 0.479 \\
\hline Mis $\leq 50 \%$ & 0.332 & Mis $\leq-10 \%$ & 0.467 & Mis $\leq-10 \%$ & 0.402 \\
\hline
\end{tabular}

Sources: WDI database and the authors' calculations.

According to the criterion of misalignment classification comparison, the average RER in overvalued (higher overvalued) observations should be greater than that in the undervalued (lower overvalued) ones; otherwise, the finding will be concluded as not reasonable. In the ratio model, the average RER decreases strictly from 0.819 when Mis $\geq 70 \%$ to 0.624 when $50 \%<$ Mis $<70 \%$ and then to 0.332 when Mis $\leq 50 \%$; the misalignment is reasonable. The same conclusion can also be obtained in the case of the BEER model. That is, both the findings from the ratio and BEER models are reasonable. However, in the Penn effect model, the average RER first decreases from 0.532 when Mis $\geq 10 \%$ to 0.400 when $-10 \%<$ Mis $<10 \%$ but then increases to 0.467 when Mis $\leq-10 \%$. Therefore, the misalignment from the Penn effect model is only partly reasonable (reasonable in the period from Mis $\geq 10 \%$ to $-10 \%<$ Mis $<10 \%$ but not reasonable in the period from $-10 \%<$ Mis $<10 \%$ to Mis $\leq-10 \%)$.

In conclusion, the statistic indexes (RMSE and MAE) and economic meaning (misalignment classification comparison) indicate that the misalignment from the BEER model is the best, the misalignment from the ratio model is somewhat better, and the misalignment from the Penn effect model is the worst. Further, based on the ratio and BEER model, the RMB RER was overvalued by about $10-20 \%$ (or more precisely, by 8-25\%) in 2011-2012, which will be discussed in the next two sections (Sections 5 and 6).

\section{WHAT CAUSED THE RMB OVERVALUATION IN RECENT YEARS?}

In this section, let's analyze the factors that caused the RMB overvaluation in 2011-2012, such as the overvaluation of about $10 \%$ from the BEER model.

\footnotetext{
${ }^{7}$ When using his RER classification comparison, we divide the whole period into three sub-periods (1980-1986, 1987-2006 and 2007-2012), and the comparison result is like that listed here. Concretely, according to the RER classification comparison, both the ratio and Penn effect modes are only partly reasonable in the whole period, but the BEER model is reasonable in the whole period.
} 
Table 6 shows the concrete changes for the RMB RER, NER, and PPP (all against the US) in 2003-2012, whose definitions are the same as in Eq. (1). We can see that in the last 10 years the RER has been appreciating, from 0.4 in 2003 to 0.66 in 2012. In 2011-2012, the RMB RER was overvalued by about $10 \%$ (based on the BEER model), which can be interpreted to say that the RMB has already excessively appreciated.

Table 6. RMB RER and relevant variables in 2003-2012

\begin{tabular}{cccccc}
\hline Year & $\begin{array}{c}\text { RER } \\
\text { (US=1) }\end{array}$ & $\begin{array}{c}\text { RER } \\
\text { misalignment }\end{array}$ & $\begin{array}{c}\text { PPP } \\
\text { (yuan/US\$) }\end{array}$ & $\begin{array}{c}\text { NER } \\
\text { (yuan/US\$) }\end{array}$ & $\begin{array}{c}\text { M2_China/ } \\
\text { M2_US }\end{array}$ \\
\hline 2003 & 0.398 & $-29.7 \%$ & 3.296 & 8.277 & $30.1 \%$ \\
2004 & 0.414 & $-30.1 \%$ & 3.427 & 8.277 & $33.7 \%$ \\
2005 & 0.421 & $-31.4 \%$ & 3.448 & 8.194 & $36.7 \%$ \\
2006 & 0.435 & $-27.6 \%$ & 3.466 & 7.973 & $42.2 \%$ \\
2007 & 0.476 & $-21.9 \%$ & 3.625 & 7.608 & $46.3 \%$ \\
2008 & 0.550 & $-5.3 \%$ & 3.823 & 6.949 & $55.1 \%$ \\
2009 & 0.552 & $-1.9 \%$ & 3.767 & 6.831 & $68.8 \%$ \\
2010 & 0.586 & $-0.1 \%$ & 3.966 & 6.770 & $84.9 \%$ \\
2011 & 0.648 & $8.8 \%$ & 4.186 & 6.461 & $98.0 \%$ \\
2012 & 0.660 & $11.4 \%$ & 4.164 & 6.312 & $109.4 \%$ \\
\hline
\end{tabular}

Sources: WDI database and the authors' calculations.

${ }^{a}$ The misalignment is obtained from the BEER model. M2 of China (M2_China) and M2 of the US (M2_US) are measured by the same currency, the US dollar.

The direct reason for the overvaluation of RMB in 2011-2012 can be traced back to Eq. (1), where the RER is composed of two parts: PPP and NER. In Table 6, we can see that both the PPP and NER have been appreciating since 2003. Concretely, the PPP exchange rate rose from 3.3 (yuans per US dollar) in 2003 to 4.2 in 2012, and the NER appreciated from 8.3 (yuans per US dollar) in 2003 to 6.3 in 2012. Therefore, it was the continuous appreciation of both the PPP and NER in 2003-2012 that led to the appreciation of the RMB and then its overvaluation in 2011-2012.

What, then, caused the appreciation of the PPP and NER? According to the definition of PPP $\left(=\mathrm{P} / \mathrm{P}^{*}\right)$, the appreciation of $\mathrm{PPP}$ is the result of the faster increase of $\mathrm{P}$ (China's price level) relative to $\mathrm{P}^{*}$ (the US's price level), which is further caused by the faster growth of the money supply in China than that in the US. Table 6 shows that the M2 of China had rapidly increased from $30 \%$ of the US in 2003 to more than $100 \%$ of the US in 2012. Another index, M2/GDP, also tells the same story. The M2/GDP in the USA was in the range of 70-90\% in 2003-2012, while M2/GDP in China was in the range of $150-190 \%$ in the same period. As for the NER appreciation, it was mainly caused by the pressure from the US. The US government hopes, as some economists argue, that the RMB appreciation can obviously reduce the US's trade deficit and increase the US's employment; see Bergsten (2010). It is under this pressure, as a response, that China appreciated its NER from 8.3 in 2003-2004 to 6.3 in the end of 2012. In July 2013, the NER was 6.2, and the degree of appreciation was $25 \%$ [ $=(8.3-6.2) / 8.3]$ or $34 \%$ [= (8.3 - 6.2) / 6.2].

In conclusion, the direct reason for the RMB RER overvaluation in 2011-2012 is the continuous appreciation of the PPP and NER, and the deep reason is the faster growth of the monetary supply of China than that of the US, along with the appreciation pressure from the US. 


\section{DOES THE CURRENT OVERVALUATION MEAN FUTURE DEPRECIATION?}

\section{(a) Current economic situation}

An overvalued currency may deteriorate external trade, decrease economic growth, lead to economic crisis, and result in great economic instability (Edwards, 1989; Alper and Civcir, 2012; Elbadawi et al., 2012). When examining China's economy, some similar things appear. As noted in the Introduction, the growth ratio of China's GDP decreased from 10.4\% in 2010 to $9.3 \%$ in 2011 and $7.8 \%$ in 2012. The growth ratio of China's exports decreased from $32.3 \%$ in 2010 to $22.3 \%$ in 2011 and $9.1 \%$ in 2012. In the first half of 2013, China's GDP grew by $7.6 \%$ and exports grew by $10.4 \%$; both decreased when compared with the same period in the last year. ${ }^{8}$ For the current not-ideal situation, a bad foreign economic environment (especially that from the US and the Europe) is a reason, but the continuous appreciated and already overvalued RER may be another reason. In addition, the political and government system, economic growth mode, employment, banking (and its relationships with local government bond issue and housing price bubble), and polarization between the rich and the poor all bring some hidden troubles to the future economic growth of China. Given this situation, the RMB should deprecate in the future in order to offer some help for the economy.

However, China has advanced its RMB internalization in recent years. In July 2009, pilot projects for the use of the RMB in cross-border trade was started in five cities. Thereafter, the areas participating in the pilot settlement in cross-border trade were expanded to 20 provinces in June 2010 and then to the whole country in August 2011. Since 2008, China has signed currency swap deals with quite a number of countries to enable bilateral trade in the local currencies of the two countries. ${ }^{9}$ According to a report by Clifford Chance, the value of payments using RMB grew by $171 \%$ in a year, from January 2012 to January 2013; and the ranking of RMB as a payment currency jumped from 20th place to 13th place from January 2012 to March 2013, pushing it past currencies like the New Zealand dollar and the Russian rouble. ${ }^{10}$ Considering the RMB internalization, the RMB should not depreciate; otherwise, foreigners will not accept it.

\section{(b) Policy proposal}

Given the conflicting demands from the economic downturn and from the RMB internalization, we suggest that the policymakers (1) depress the too-fast rise of the domestic price level and (2) keep the NER stable (not appreciating it continuously as before).

As for the domestic price level, it has a relationship with the PPP $\left(=\mathrm{P} / \mathrm{P}^{*}\right)$ rate and then with the RER (= PPP / NER). Table 6 shows that the PPP kept on appreciating in 2003-2012 (except in 2011-2012), which means that the rise of the price level of China was always faster than that of the US. By depressing the too-fast rise of the domestic price level, given the US price level, China can make the PPP appreciation slow down. This can partly decrease the fast appreciation of the RER. A direct measure to depress China's price level, following the discussion above in Section 5, is to

\footnotetext{
${ }^{8}$ News release (in Chinese), http://cn.reuters.com/article/cnBizNews/idCNL4S0FL0H420130715?sp=true

${ }^{9}$ Renminbi internalization (in Chinese), http://baike.baidu.com/view/2099520.htm

The internationalization of the yuan,

http://www.forbes.com/sites/jackperkowski/2012/02/23/the-internationalization-of-the-yuan/

${ }^{10}$ New developments accelerate Renminbi internationalisation,

http://www.cliffordchance.com/publicationviews/publications/2013/07/new_developmentsacceleraterenminb0.html
} 
control its money supply (not let its money supply grow so quickly). Based on the WDI, we can calculate that the compound annual growth ratio of M2 in China from 2003 to 2012 was $18.5 \%$, which is about three times the same ratio $(6.2 \%)$ in the US in the same period. The price level rise of China (and thus the PPP rate) will slow down if the growth of its money supply slows down.

As for the NER, it is like a tax that the government exerts on its export and import enterprises. When priced higher, NER benefits import enterprises; when priced lower, NER benefits export enterprises. For example, after the RMB NER (yuans per US dollar) appreciated from 8.3 in 2004 to 6.2 in July 2013, one US dollar (the same amount of foreign income) exchanged for 2 yuan less in China's domestic market. It was as if the government exerted an additional $25 \%$ tax $[=(8.3-6.2) /$ 8.3] on export goods. Besides the NER appreciation, the rise of labor costs and material prices again squeezed the margins of export enterprises, which are mostly low value-added (such as numerous labor intensive ones in the Pearl River Delta). China's export enterprises have been hard hit by the above factors together with the deteriorating international environment, though some measures can offset the negative effect (such as the direct use of RMB in some bilateral trades) in some degree. Therefore we propose that the NER should remain stable and that greater appreciation must be avoided. By keeping the NER level stable, the advances of RMB internationalization are not negatively influenced. At the same time, it will not drive the appreciation of the RMB RER.

Zhang (2012c) studied 18 typical countries and areas that experienced a great degree of RER appreciation and argued that an appreciation speed of 3.2\% per year (the actual appreciation speed of the RMB RER in 1994-2010) for RMB RER is more realistic than 6.7\% (that in 2005-2010). In their RER appreciation periods, four neighboring Asian countries and areas had an appreciation speed around 3.2\% (Korean won at 3.6\% and Japanese yen 3.5\% above this value, and Taiwan dollar 1.9\% and Singapore dollar 1.6\% below this value). From 2005 to 2012, the compound annual appreciation speed was $6.6 \%$, near the $6.7 \%$ mark. Considering the not-ideal economic situation of China and its less robust economic status relative to the four industrial neighbors, we do not think that China can tolerate such a fast appreciation as 6.6-6.7\% per year (nearly two times of that of Korea and Japan and more than three times that of Taiwan and Singapore). In our opinion, China should adopt the policies discussed above to stop such fast appreciation of its RER in the future.

\section{CONCLUSION}

We use three models (the ratio, Penn effect and BEER models) to value the RMB RER against the US dollar in 1980-2012. The ratio model is modified because of the great different national conditions between China and the US, while the Penn effect and BEER models are used in panel data settings. The statistical indexes (RMSE and MAE) and economic meaning (misalignment classification comparison) indicate that the misalignment from the BEER model is the best, the misalignment from the ratio model is somewhat better, and the misalignment from the Penn effect model is the worst. Concretely, based on the ratio and BEER models, the RMB RER was overvalued by about 10-20\% in 2011-2012. This occurred, first, because far faster growth of M2 in China than that in the US has led to China's higher price level and then the appreciation of PPP. Second, the RMB NER kept on appreciating since 2005 because of the pressure from the US.

Since 2010 and especially in the first half of 2013, China's economic downtown has demanded that its currency depreciate. But, simultaneously, China had greatly advanced RMB internalization in recent years, which demands that the RMB not depreciate. Actually, China has kept on 
appreciating its currency since 2005, both in nominal and real terms. Considering all these factors, we propose that the policymakers may not depreciate the RMB but must suppress the RMB's greater appreciation. Continuously appreciating the already overvalued currency in the future is wrong. Though it can meet the foreigners' demand for RMB internalization, it will do harm to the economy. To suppress the RMB RER appreciation too fast (and to avoid excessive overvaluation), policymakers should (1) control the excessive money supply to suppress the PPP appreciation and (2) not appreciate the NER too fast. Before the internal and external economic environment greatly changes, the best policy is to keep the exchange rates, both NER and RER, as unchangeable as possible.

\section{REFERENCES}

Alper, A.M., \& Civcir, I. (2012). Can overvaluation prelude to crisis and harm growth in Turkey. Journal of Policy Modeling, 34(1), 112-131

Balassa, B. (1964). The purchasing-power parity doctrine: A reappraisal. Journal of Political Economy, 72(6), 584 596.

Bénassy-Quéré, A., \& lahrèche-Révil, A. (2008). Is Asia responsible for exchange rate misalignments within the G20? Pacific Economic Review, 13(1), 46-61.

Bergsten, C. F. (2010). Correcting the Chinese exchange rate: An action plan. Testimony before the Committee on Ways and Means, US House of Representatives, March 24.

Bussière, M., Ca’ Zorzi, M., Chudík, A., \& Dieppe, A. (2010). Methodological advances in the assessment of equilibrium exchange rates. European Central Bank Working Paper No. 1151.

Chang, G., \& Shao, Q. (2004). How much is the Chinese currency undervalued? A quantitative estimation. China Economic Review, 15(3), 366-371

Cheung, Y., \& Chinn, M. (1998). Integration, cointegration and the forecast consistency of structural exchange rate models. Journal of International Money and Finance, 17(5), 813-830.

Cheung, Y., Chinn, M., \& Fujii, E. (2007). The overvaluation of renminbi undervaluation. Journal of International Money and Finance, 26(5), 762-785.

Cheung, Y., Chinn, M., \& Fujii, E. (2010). Measuring renminbi misalignment: Where do we stand? Korea and the World Economy, 11(2), 263-296.

Clark, P., \& MacDonald, R. (1998). Exchange rates and economic fundamentals: A methodological comparison of BEERs and FEERs. IMF Working Paper No. 98/67.

Dubas, J. M. (2009). The importance of the exchange rate regime in limiting misalignment. World Development, $37(10), 1612-1622$.

Dunaway, S., Leigh, L., \& Li, X. (2009). How robust are estimates of equilibrium real exchange rates: The case of China. Pacific Economic Review, 14(3), 361-375.

Edwards, S. (1989). Exchange rate misalignment in developing countries. The World Bank Research Observer, 4(1), $3-21$.

Égert, B., Halpern, L., \& MacDonald, R. (2006). Equilibrium exchange rates in transition economies: Taking stock of the issues. Journal of Economic Surveys, 20(2), 257-324.

Elbadawi, I. A., Kaltani, L., \& Soto, R. (2012). Aid, real exchange rate misalignment, and economic growth in Sub-Saharan Africa. World Development, 40(4), 681-700

Frankel, J. (2006). On the yuan: The choice between adjustment under a fixed exchange rate and adjustment under a flexible rate. CESifo Economic Studies, 52(2), 246-275. 
Funke, M., \& Rahn, J. (2005). Just how undervalued is the Chinese renmimbi? The World Economy, 28(4), 465-89.

Garroway, C., Hacibedel, B., Reisen, H., \& Turkisch, E. (2012). The renminbi and poor-country growth. The World Economy, 35(3), 273-294.

Isard, P. (2007). Equilibrium exchange rates: Assessment methodologies. IMF Working Paper No. 296.

Ito, T., Isard, P., \& Symansky, S. (1997). Economic growth and real exchange rate: An overview of the BalassaSamuelson hypothesis in Asia. NBER Working Paper No. 5979.

Kravis, I. B., \& Lipsey, R. E. (1982). Towards an explanation of national price levels. NBER Working Paper No. 1034.

Lopez-villavicencio, A., Mazier, J., \& Saadaoui, J. (2012). Temporal dimension and equilibrium exchange rate: A FEER/BEER comparison. Emerging Markets Review, 13(1), 58-77.

MacDonald, R. (1999). Exchange rate behaviour: are fundamentals important? The Economic Journal, 109 (459), 673-691.

Maeso-Fernandez, F., Osbat, C., \& Schnatz, B. (2006). Towards the estimation of equilibrium exchange rates for transition economies: Methodological issues and a panel cointegration perspective. Journal of Comparative Economics, 34 (3) , 499-517.

Meese, R., \& Rogoff, K. (1983). Empirical exchange rate models of the seventies: Do they fit out of sample? Journal of International Economics, 14 (1-2), 3-24.

Rogoff, K. (1996). The purchasing power parity puzzle. Journal of Economic Literature, 34(2), 647-668.

Samuelson, P. (1994). Facets of Balassa-Samuelson thirty years later. Review of International Economics, 2(3), 201226.

Sato, K., Shimizu, J., Shrestha, N., \& Zhang, Z. (2012). New estimates of the equilibrium exchange rate: The case for the Chinese renminbi. The World Economy, 35(4), 419-443.

Wooldridge, J. M. (2006). Introductory Econometrics: A Modern Approach. Third edition. Mason, OH: Thomson South-Western.

Yang, J., \& Bajeux-Besnainou, I. (2006). Is the Chinese currency undervalued? International Research Journal of Finance and Economics, (2), 106-130.

Zhang, Z. (2012a). A simple model and its application in the valuation of eleven main real exchange rates. International Research Journal of Finance and Economics, (97), 55-59.

Zhang, Z. (2012b). A comparison of the BEER and Penn effect models via their applications in the renminbi valuation. International Research Journal of Finance and Economics, (97), 138-154.

Zhang, Z. (2012c). RMB undervaluation and appreciation. http://ideas.repec.org/p/pra/mprapa/40978.html. 